С.М. Звиглянич ${ }^{1}$, М.О. Романов ${ }^{2}$, М.Ф. Линник ${ }^{3}$, Т.А. Позовна ${ }^{2}$

${ }^{1}$ Харківський начіональний університет Повітряних Сил ім. І. Кожедуба, Харків

${ }^{2}$ Державне Космічне Агентство України, Головний Центр Спеціального Контролю, Харків

${ }^{3}$ Військовий інститут танкових військ НТУ “ХПІ”, Харків

\title{
ОЦІНКА МОЖЛИВОСТЕЙ КОМПЛЕКСУ ОЗБРОЄННЯ В ХОДІ ПЛАНУВАННЯ УРАЖЕННЯ ВИЯВЛЕНИХ ОБ'ЄКТІВ
}

В статті розглядається підхід до оцінювання бойових можливостей комплексів озброєння різних типів під час планування ураження виявлених иілей. Сучасні комплекси озброєння представляються у якості складних антропотехнічних систем, які функціонують в режимі жорсткого часового обмеження. Це, в свою чергу, зумовлює підвищення вимог як до технічної готовності комплексу озброєння по виконанню функиіональних задач, так і підвищення вимог до номерів бойових розрахунків, які безпосередньо управляють иією зброєю і використовують засоби за призначенням. Запропоновано загальний підхід до оцінки можливостей комплексів озброєння різного призначення. Даний підхід опирається на иілком об'єктивні показники. Проста кількісна оцінка дає можливість на основі введених критеріїв проводити оцінювання існуючих однотипних комплексів озброєння. Цей підхід може лягти в основу методик для оцінювання готовності конкретних типів комплексів озброєння. За результатами такого оцінювання з'являється можливість прогнозування рівня готовності комплексів озброєння до бойового застосування.

Ключові слова: технічна категорія, коефічієнт готовності, кваліфікація номерів розрахунку.

\section{Вступ}

Постановка проблеми. На даний час спостерігається тенденція значного ускладнення комплексів озброєння як людино-машинних систем. Зростає технічна оснащеність комплексів та систем озброєння, з'являється все більше роботизованих систем. У зв'язку з цим постійно підвищуються вимоги і до персоналу, який обслуговує це озброєння, і до номерів бойових розрахунків, які використовують зразки озброєння під час виконання завдань за призначенням.

Постійна готовність до застосування комплексів озброєння стає одним з визначальних чинників бойової готовності військ (сил) у цілому.

Оцінити готовність комплексу озброєння до застосування як системи, що об'єднує в одне ціле особовий склад і техніку (зразки озброєння), є актуальним завданням. Така оцінка не повинна включати елементи суб'єктивності і максимально бути об'єктивною. При цьому оцінка повинна мати фізичний сенс і бути обчислюваною.

Аналіз останніх досліджень і публікацій. Останні декілька десятиліть військові фахівці вважають часом інтенсивного розвитку так званої “інтелектуальної зброї”. Оцінка готовності таких людино-машинних комплексів на основі розрахунку показників надійності технічних систем по заданій структурі несе в собі певну складність і значні часові витрати на підготовку початкових даних [1-3].
Існуючі моделі технічного обслуговування i ремонту систем різного призначення, як основи оцінки їх готовності до застосування, базуються на математичному апараті, що вимагає певної статистики для проведення такого аналізу [4-6].

При цьому слід зазначити, що досвід експлуатації озброєння і військової техніки дає підстави робити висновки про готовність комплексів озброєння до бойового застосування на підставі їх технічної готовності.

Метою статті $є$ визначення підходу з оцінювання готовності до бойового застосування комплексів озброєння на основі обчислюваних показників (характеристик), які мають ясний фізичний сенс, та, в цілому, дозволяють проводити кількісну оцінку потенційної можливості зброї.

\section{Виклад основного матеріалу}

3 урахуванням сучасних поглядів на ведення бойових дій, потрібно підходити до засобів ураження як до елементів комплексу озброєння. У даному випадку комплекс озброєння представляється у вигляді антропотехнічної системи з системою управління та засобами спостереження і розвідки. Засоби спостереження і розвідки можуть бути безпосередньо комплексовані в комплекс озброєння або ж розглядатимуться як деякі зовнішні системи, що забезпечують комплекс озброєння відповідною інформацією. Розглянемо основні характеристики засобів ураження. 
Важливими чинниками будемо вважати такі характеристики як потужність бойової частини i точність ураження об'єктів противника [7].

Традиційно ці характеристики представляються через вагу бойової частини, приведеної до тротилового еквіваленту $P_{б ч}[\kappa 2]$, та імовірність відхилення у колі $E_{б ч}[M]$.

Роботу системи управління комплексу озброєння оцінимо через тривалість циклу управління [8], iï представимо як

$$
T_{ц У}=T_{\Pi Р}+T_{Д}+T_{\Pi \Pi},
$$

де $T_{\Pi Р}$ - час прийняття рішення на нанесення удаpy, $T_{д}-$ час доведення наказу на нанесення удару безпосередньо до бойового розрахунку, $T_{\text {ПП }}$ - час підготовки до застосування обраного засобу ураження (підготовка до пуску ракети для ракетного комплексу, підготовка до вильоту літака ударної авіації та ін.). Вимірність для часу оберемо [c].

Для кожного засобу ураження доволі відчутними $є$ такі показники, як час доставки самого засобу ураження (час удару) $T_{y}$ і $P_{\Pi}-$ імовірність того, що засоби ураження досягнуть об'єкта ураження.

$$
T_{y}=\frac{R}{V_{y}}
$$

де $R[M]$ - відстань до об'єкта ураження;

$V_{Y}[\mathcal{M} / c]-$ швидкість засобу ураження.

Імовірність в значній мірі характеризує можливості противника по збереженню живучості його військових об'єктів, або ж об'єктів інфраструктури [9]. Систему спостереження і розвідки доцільно оцінювати за допомогою часу викриття об'єкту ураження $T_{B}[c]$.

Цей час залежить від самого об'єкту ураження. Тому введемо для розгляду такий показник об'єкту ураження, як його площа $S_{O \Pi}\left[M^{2}\right]$.

Після узагальнення вищенаведеного, введемо показник $F_{K}$, який характеризує можливості обраного зразка (типу) озброєння з ураження відповідного об'єкта ураження:

$$
F_{K}=\left(\frac{P_{Б Ч} S_{O \Pi}}{\left(T_{Ц У}+T_{У}\right) T_{B} E_{Б Ч}}\right) P_{\Pi} .
$$

Наведений показник можливості комплексу озброєння з ураження обраного об'єкта представимо через його “здатність” виконати такого роду задачу.

У найзагальнішому трактуванні, комплекс озброєння (КО) - це сукупність зразків військової техніки, функціонально пов'язаних і спільно використовуваних для вирішення бойових завдань. Він включає такі основні компоненти [10]: a) вогневу установку (зброя);

b) систему управління;

c) розрахунок (екіпаж).

Для подальших розрахунків розділимо агрегати і системи КО на бойові і технологічні. Бойові можливості цих агрегатів і систем багато в чому визначаються їх технічним станом.

Технічний стан опосередковано оцінюється відповідною категорією:

- 1-а категорія - нові агрегати і системи справні та придатні до бойового застосування;

- 2-а категорія - агрегати і системи, що знаходяться в експлуатації та не виробили визначений міжремонтний ресурс;

- 3-а категорія - агрегати і системи, що виробили технічний ресурс до середнього ремонту;

- 4-а категорія - агрегати і системи, що виробили міжремонтний ресурс (період) експлуатації до капітального ремонту, або потребують проведення капітального ремонту за технічним станом;

- 5-а категорія - агрегати і системи непридатні для бойового використання, відновлення яких технічно неможливе або економічно недоцільне.

Оцінку стану агрегатів і систем (бойових і технологічних) КО проведемо з використанням введеної порядкової (рангової) шкали (табл. 1) [11].

Таблиця 1

Порядкова шкала оцінки агрегатів і систем

\begin{tabular}{|c|c|c|c|c|c|}
\hline Категорія & $1-\mathrm{a}$ & $2-\mathrm{a}$ & $3-я$ & $4-\mathrm{a}$ & $5-\mathrm{a}$ \\
\hline Оцінка & 9 & 7 & 5 & 3 & 1 \\
\hline
\end{tabular}

Джерело: розроблено авторами.

Результат оцінки представляється як:

$$
F_{T}=\sum_{i=1}^{n} a_{i}+\sum_{j=1}^{m} b_{j},
$$

де $a_{i}$ - оцінка $i$-го бойового агрегату (системи);

$b_{j}$ - оцінка $j$-го технологічного агрегату (системи);

$n$ - кількість бойових агрегатів (систем) в КО;

$m$ - кількість технологічних агрегатів (систем) в КО.

Стан агрегату (системи) можна оцінити коефіцієнтом готовності, який характеризує те, що агрегат (система) опиниться в працездатному стані в довільний момент часу, крім планованих періодів, впродовж яких застосування агрегату (системи) за призначенням не передбачається. Коефіцієнт готовності [12] представляється як:

$$
K_{\Gamma}=\frac{T_{\Phi}}{T_{\Pi}},
$$

де $T_{\Phi}$ - фактичний час роботи агрегату (системи);

$T_{\Pi}-$ повний час даного інтервалу (як правило, 
коефіцієнт готовності визначається при проведенні річного регламенту). 3 урахуванням коефіцієнта готовності уточнену оцінку стану КО можна представити виразом

$$
F_{T}^{*}=\sum_{i=1}^{n} a_{i} k_{a_{i}}+\sum_{j=1}^{m} b_{j} k_{b_{j}},
$$

де $k_{a_{i}}, k_{b_{j}}-$ коефіцієнти готовності відповідних агрегатів (систем).

Об'єктивна оцінка можливостей бойового розрахунку повинна враховувати можливості кожного номера розрахунку (військовослужбовця).

Для військовослужбовця вона, передусім, оцінюється рівнем його кваліфікації (підготовки). Кваліфікація ж визначається класністю.

Для проведення оцінки можливостей номерів бойового розрахунку введемо порядкову (рангову) шкалу (табл. 2) [11].

Таблиця 2

Порядкова шкала оцінки номерів бойового розрахунку

\begin{tabular}{|c|c|c|c|c|c|}
\hline Класність & $\begin{array}{c}\text { Майс- } \\
\text { тер }\end{array}$ & $\begin{array}{c}1-и ̆ \\
\text { клас }\end{array}$ & $\begin{array}{c}2-и ̆ \\
\text { клас }\end{array}$ & $\begin{array}{c}3 \text {-й } \\
\text { клас }\end{array}$ & Відсутня \\
\hline Оцінка & 9 & 7 & 5 & 3 & 1 \\
\hline
\end{tabular}

Джерело: розроблено авторами.

3 урахуванням важливості ролі начальника розрахунку пропонується оцінювати його кваліфікацію (класність) окремо. Тоді оцінка можливостей бойового розрахунку представляється як

$$
F_{J}=K_{H p}+\sum_{i=1}^{L} k_{i}
$$

де $K_{н p}$ - оцінка кваліфікації начальника розрахунку;

$k_{i}$ - оцінка кваліфікації $i$-го номера розрахунку;

$L$ - кількість номерів у бойовому розрахунку.

У бойовій роботі номерів розрахунку виняткову роль грає їх злагодженість. Оцінимо злагодженість бойового розрахунку, виходячи з часу їх спільної роботи за порядковою (ранговою) шкалою (табл. 3).
Таблиця 3

Порядкова шкала оцінки злагодженості бойового розрахунку

\begin{tabular}{|c|c|c|c|c|}
\hline Тривалість & $\begin{array}{c}\text { Більше } \\
\text { 5 років }\end{array}$ & $\begin{array}{c}\text { Більше } \\
\text { 3 років }\end{array}$ & $\begin{array}{c}\text { Більше } \\
\text { за рік }\end{array}$ & $\begin{array}{c}\text { Менше } \\
\text { року }\end{array}$ \\
\hline $\begin{array}{c}\text { Коефіцієнт } \\
k_{s_{l}}\end{array}$ & 1 & 0.8 & 0.6 & 0.4 \\
\hline
\end{tabular}

Джерело: розроблено авторами.

3 урахуванням злагодженості оцінка можливостей бойового розрахунку представляється як

$$
F_{J}^{*}=\left(K_{\mu p}+\sum_{i=1}^{L} k_{i}\right) k_{s_{l}},
$$

де $k_{s_{l}}$ - коефіцієнт злагодженості бойового розрахунку.

Таким чином, з урахуванням вищенаведеного, введемо для розгляду узагальнений показник, який характеризує можливості конкретного комплексу озброєння з ураження виявленої цілі.

При цьому враховується технічний стан комплексу озброєння і кваліфікація номерів бойового розрахунку:

$$
F_{\Sigma}=F_{K} F_{T}^{*} F_{J}^{*}
$$

\section{Висновки}

Запропоновано загальний підхід до оцінки можливостей комплексів озброєння різного призначення при плануванні ураження виявлених об'єктів. Він опирається на цілком об'єктивні показники, які мають ясний фізичний сенс, є обчислювальними та, в цілому, дозволяють проводити кількісну оцінку потенційної можливості зброї. Проста кількісна оцінка дає можливість на основі введених показників проводити оцінювання існуючих однотипних комплексів озброєння.

Цей підхід може лягти в основу методик для оцінювання готовності конкретних типів комплексів озброєння. Слід зазначити, що наведені в табл. 1-3 шкали на основі експертних оцінок можуть в ході проведення оцінювання уточнюватися.

\section{Список літератури}

1. Морозов Н. А. Теоретические основы качественного анализа больших военных систем. Москва : МО, 2003.

2. Бонин А. С. Основные положения методических подходов к оценке боевых потенциалов и боевых возможностей авиационных формирований. Военная мыслль. 2008. № 1. С. 43-47.

3. Буравлев А. И. Модель оценки эффективности боевых систем. Военная мыслль. 2009. № 5. С. 39-43.

4. Брезгин В. С. Методика оценки предельного боевого потенциала средств вооружения и военной техники. Вооружение и экономика. 2009. № 2(6). С. 40-41.

5. Буравлев А. И, Цырендоржиев С. Р., Брезгин В. С. Основы методологического подхода к оценке боевых потенциалов образцов ВВТ и воинских формирований. Вооружение и экономика. 2009. № 3(7). С. 4-12.

6. Брезгин В. С., Буравлев А. И. Ометодологии оценки боевых потенциалов вооружения и военной техники и воинских формирований. Военная Мысль. 2010. № 8. С. 41-48.

7. Средства поражения и боеприпасы : учеб. пособие / Бабкин А. В. и др.; под общ. ред. В.В. Селиванова. Москва : МГТУ им. Н.Э. Баумана, 2008. 984 с. 
8. Баранюк В. В. Единое информационное пространство Вооруженных Сил РФ: проблемы создания. Военная мыслль. 2003. № 2. С. 36-38.

9. Воробьев И. Н., Киселев В. А. Направления развития тактической разведки. Военная мысль. 2014. № 5. С. 10-17.

10. Бойко А. А. Способ аналитического моделирования боевых действий. Системы управления, связи и безопасности. 2019. № 2. С. 1-27.

11. Саати Т. Принятие решений. Методы анализа иерархий. Москва : Радио и связь, 1993. 278 с.

12. Надежность и эффективность в технике: справочн. Т. 8: Эксплуатация и ремонт / Авдуевский В. С. и др. Москва : Машиностроение, 1990. 321 с.

Надійшла до редколегії 02.11.2021

Схвалена до друку 14.12.2021

\section{Відомості про авторів:}

\section{Звиглянич Сергій Миколайович}

кандидат технічних наук старший науковий співробітник старший науковий співробітник

Харківського національного університету

Повітряних Сил ім. І. Кожедуба,

Харків, Україна

https://orcid.org/0000-0003-2419-8093

\section{Романов Максим Олексійович}

начальник відділу

Державного Космічного Агентства

Головного Центру Спеціального Контролю,

Харків, Україна

https://orcid.org/0000-0003-3366-4631

\section{Линник Микола Федорович}

кандидат технічних наук

доцент кафедри військового інституту

танкових військ НТУ "ХПІ",

Харків, Україна

https://orcid.org/0000-0002-6631-7102

\section{Позовна Тетяна Анатоліївна}

інженер АСП “Харків” Державного космічного агентства

Головного Центру Спеціального Контролю,

Харків, Україна

https://orcid.org/0000-0001-6711-2582

\section{Information about the authors:}

\section{Sergey Zviglyanich}

$\mathrm{PhD}$ in Engineering Senior Researcher

Senior Researcher

of Ivan Kozhedub Kharkiv

National Air Force University,

Kharkiv, Ukraine

https://orcid.org/0000-0003-2419-8093

\section{Maxim Romanov}

Head of Department

of State Spase Agency Center

of Special Control,

Kharkiv, Ukraine

https://orcid.org/0000-0003-3366-4631

\author{
Nikolay Linnik \\ $\mathrm{PhD}$ in Engineering \\ Associate Professor of Military Institute \\ of Tank Troops of the NTU "Kharkiv", \\ Kharkiv, Ukraine \\ https://orcid.org/0000-0002-6631-7102
}

\section{Tetjana Pozovna}

Ingineer of ASP "Kharkiv"

State Spase Agency Center of Special Control,

Kharkiv, Ukraine

https://orcid.org/0000-0001-6711-2582

\section{ОЦЕНКА ВОЗМОЖНОСТЕЙ КОМПЛЕКСА ВООРУЖЕНИЯ В ХОДЕ ПЛАНИРОВАНИЯ ПОРАЖЕНИЯ ВЫЯВЛЕННЫХ ОБЪЕКТОВ}

\section{С.Н. Звиглянич, М.А. Романов, Н.Ф. Линник, Т.А. Позовная}

В статье рассмотрен подход к оиенке боевых возможностей комплексов вооружения различных типов при планировании поражения выявленных целей. Современные комплексы вооружения представляются как сложные антропотехнические системы, функиионирующие в режиме жесткого временного ограничения. Это обусловливает повышение требований как к технической готовности комплекса вооружения выполнять функциональные задачи, так и повышение требований к номерам боевых расчетов непосредственно управляющих этим оружием. Системы комплекса предлагается рассматривать в совокупности как боевые и технологические. Каждая из систем находится в соответствующей категории, что определяет ее потенциальные возможности по выполнению своих функиий. Учет этого положения с одновременным учетом коэффициента готовности для каждой из систем позволяет реально оценить технические возможности комплекса на текущий момент времени. Несомненно, на боевые возможности оказывает самое непосредственное влияние подготовленность номеров боевого расчета к ведению боевых действий. Этот фактор предлагается оценивать путем учета классности номеров боевого расчета, а также через слаженность их действий в ходе боевой работы. Одним из определяющих факторов оиенки возможностей комплекса вооружения является учет его огневой мощности. Наиболее полно огневая мощь выражается через мощность средства поражения и его точность. В самом общем виде практически для всех комплексов вооружения здесь следует рассматривать мощность боевой части в тротиловом эквиваленте и точность, выражаемую через вероятное отклонение (круговое вероятное отклонение). Жесткие временные рамки ведения боя накладывают свои ограничения на боевые возможности комплекса вооружения, которые предлагается выражать через интегрированный показатель средств разведки как время вскрытия объекта поражения, а также возможное время нанесения удара после получения иелеуказаний.

Ключевые слова: техническая категория, коэффициент готовности, квалификация номеров расчета. 


\section{ASSESSMENT OF THE CAPABILITIES OF THE WEAPONS COMPLEX IN THE DEFEAT OF IDENTIFIED OBJECTS}

S. Zviglyanich, M. Romanov, N. Linnik, T. Pozovna

The article discusses an approach to assessing the combat capabilities of weapon systems of various types when planning the destruction of identified targets. Modern weapon systems are presented as complex anthropotechnical systems operating under a strict time constraint. This leads to increased requirements for both the technical readiness of the weapons complex to perform functional tasks, and for the increased requirements for the numbers of combat crews directly controlling these weapons. These systems of the complex are proposed to be considered in aggregate as combat and technological. Each of the systems is in the corresponding category, which determines its potential for performing its functions. Taking into account this situation, while taking into account the availability factor for each of the systems, makes it possible to realistically assess the technical capabilities of the complex at the current moment in time. Undoubtedly, the combat capabilities are directly influenced by the preparedness of the combat crew numbers for the conduct of hostilities. This factor is proposed to be assessed by taking into account the class of numbers of the combat crew, as well as through the coherence of their actions in the course of combat work. One of the determining factors in assessing the capabilities of an armament complex is taking into account its firepower. Firepower is most fully expressed through the power of the weapon and its accuracy. In the most general form, for almost all weapon systems, the power of the warhead in TNT and accuracy, expressed in terms of probable deviation (circular probable deviation), should be considered here. The strict time frames for conducting a battle impose their own restrictions on the combat capabilities of the weapons complex, which are proposed to be expressed through the integrated indicator of reconnaissance means as the time of opening the target, as well as the possible time of striking after receiving target designations.

Keywords: technical category, availability factor, qualification of settlement numbers. 